最適化手法を用いた而震設計の信賴性レベルに関するー考察

$\begin{array}{llr}\text { 京都大学工学部 } & \text { 正員 } & \text { 山田善- } \\ \text { 京都大学工学部 } & \text { 正員 } & \text { ○古川告里 } \\ \text { 広島県 } & \text { 正員 } & \text { 福原真 }\end{array}$

\title{
上去元がき
}

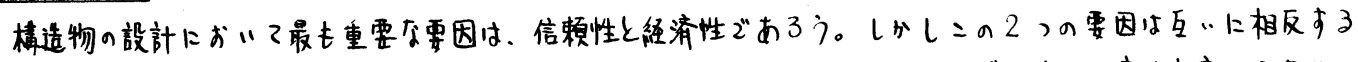

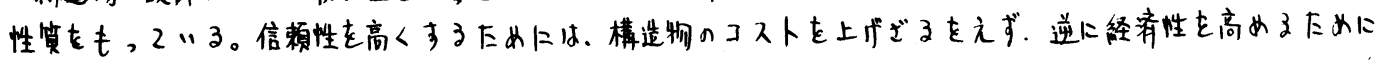

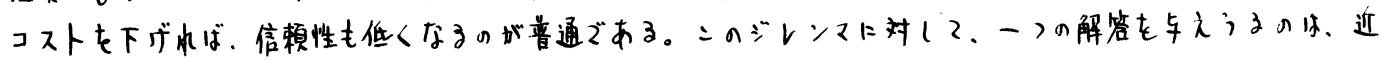

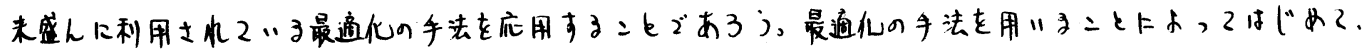

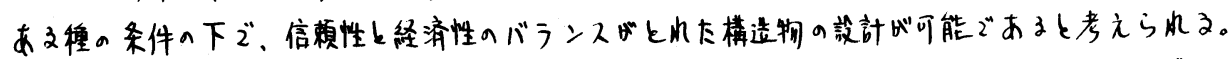

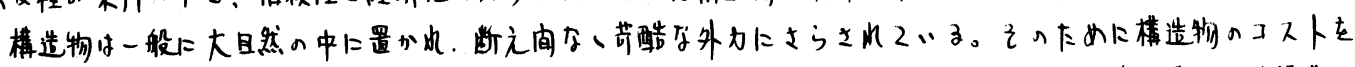



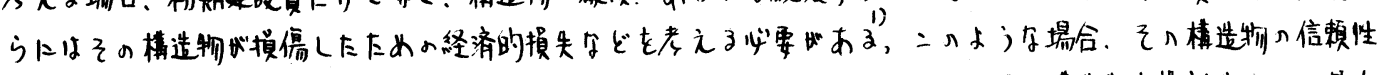

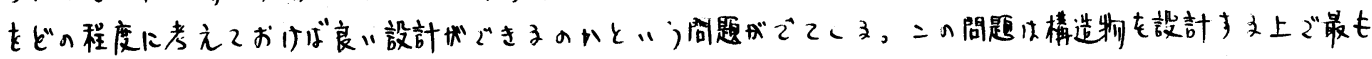

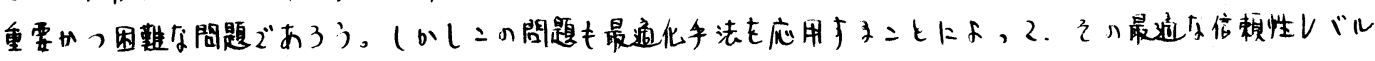
を求めることが可能である。

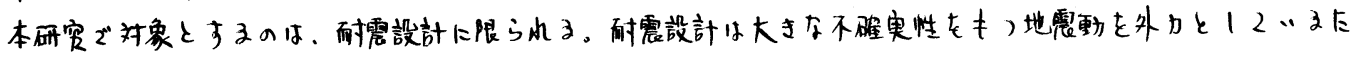







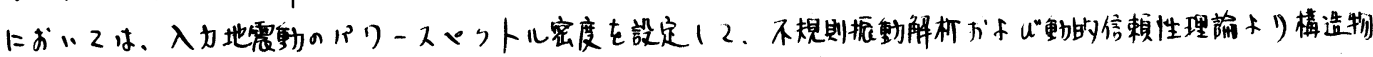

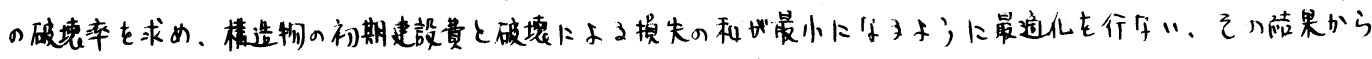





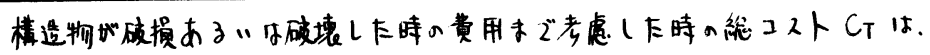

$$
C_{T}=C_{I}+C_{F}
$$

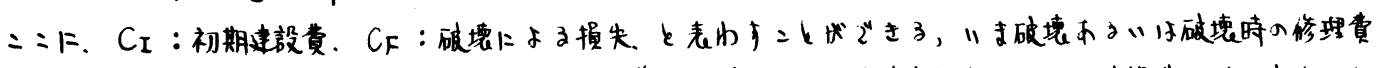

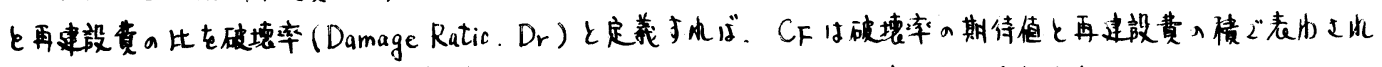

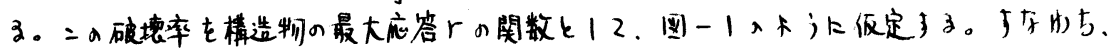

$$
D_{r}(r)=\left\{\begin{array}{cl}
0 & \left(r<r_{a}\right) \\
\left(\frac{r-r_{a}}{r_{l}-r_{a}}\right)^{\nu} & \left(r_{a} \leqq r \leqq r_{l}\right) \\
1 & \left(r_{l}<r\right)
\end{array}\right.
$$

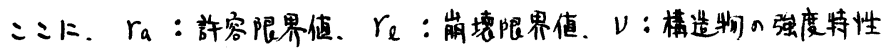
による定数。ごあ子。棈造物の最大应答值の確率分布 $F(r)$ は心答の初

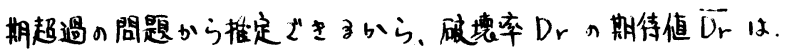

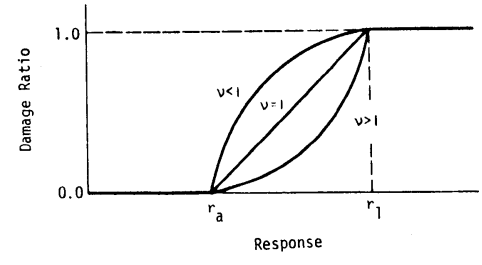

国一1破壊率関数

$$
\overline{D_{r}}(r)=\int_{r_{a}}^{r_{l}}\left(\frac{r-r_{a}}{r_{l}-r_{a}}\right)^{\nu} \frac{d}{d r} F(r) d r+\int_{r_{l}}^{\infty} \frac{d}{d r} F(r) d r
$$


として求めることができる。多自由度系模造物の遇動方程式は次のように表現士れる。

$$
M \ddot{x}+\mathbb{C} \dot{x}+\mathbb{K} x=-M \ddot{z}
$$

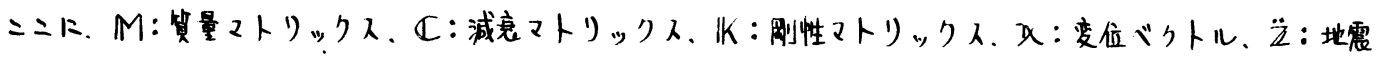



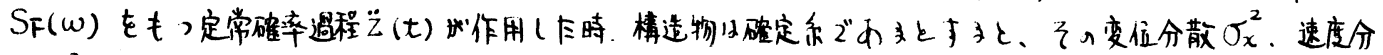
散 $\sigma_{\dot{x}}^{2}$ \&.

$$
\begin{aligned}
& \sigma_{x}^{2}=\sum_{i} \phi_{i}^{2} T_{i}^{2} \int_{-\infty}^{\infty}\left|H_{i}(\omega)\right|^{2} S_{F}(\omega) d \omega \\
& \sigma_{\dot{x}}^{2}=\sum_{i} \phi_{i}^{2} \Gamma_{i}^{2} \int_{-\infty}^{\infty} \omega^{2}\left|H_{i}(\omega)\right|^{2} S_{F}(\omega) d \omega
\end{aligned}
$$

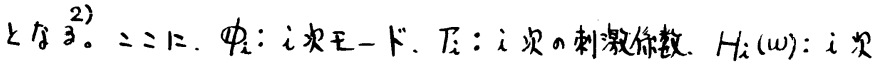
の周波数应答関数。乙゙ある。二の时最大応答の限界值入の初期超過が术

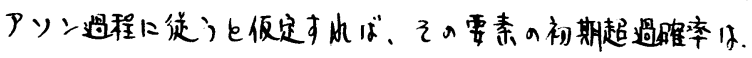

$$
F_{e}(\lambda)=1-\exp \left\{-\frac{T}{\pi} \frac{\sigma_{\dot{x}}}{\sigma_{x}} \exp \left(-\frac{\lambda^{2}}{2 \sigma_{x}^{2}}\right)\right\}
$$


体ごは。

$$
F(\lambda)=\sum_{j} F e_{j}(\lambda)
$$

となる。式(8)で入を变数とみな世ば最大応答の挽率分布を与之る。う 、結局目的米数である式(1)小。

$$
C_{T}=C_{I}+C_{R} \cdot\left\{\int_{r_{a}}^{r_{l}}\left(\frac{r-r_{a}}{r_{l}-r_{a}}\right)^{\nu} \frac{d}{d r} F(r) d r+\int_{r_{l}}^{\infty} \frac{d}{d r} F(r) d r\right\}
$$



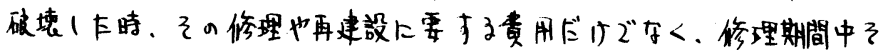

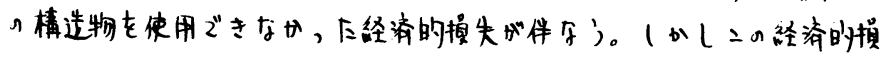



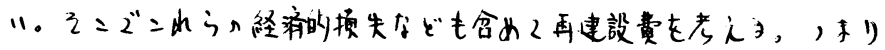

$$
C_{R}=\alpha \cdot C_{I}
$$

と12、C C $を$ を损失率(Loss Ratio) xと初期建䚺黄の棈と1く表わし

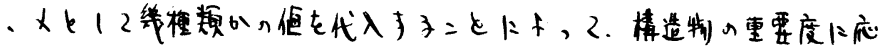



$$
C_{T}=C_{I}+\overline{D_{r}} \cdot \alpha \cdot C_{I}
$$

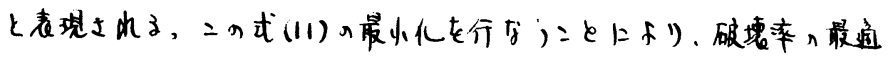

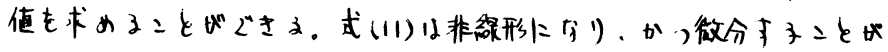

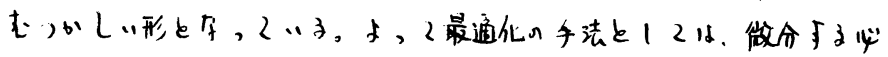

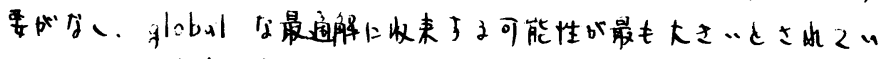



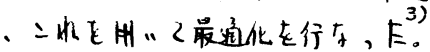

\section{3. 数值計算例およU゙考察}



匈一2 |スパン|層うーメン

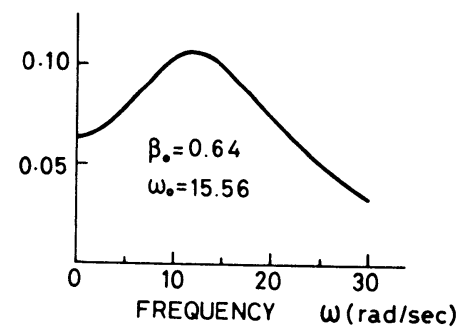

图一ーパワースハクトル密度関数 (フィルタードホワイト)イズ)

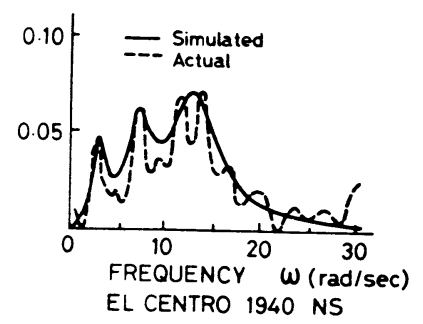

图ー4パクースペクトル密度関数

(EI Centro 1940 NS)



国一5ハリースベトル宽度関数

(Taft 1952 N21E) 


\section{1 はスパン|詹うーメントおりる計算例}

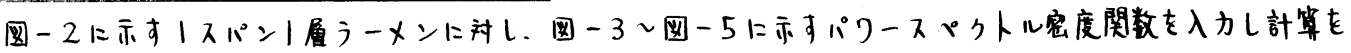
行子、乍。計算上際し、設計变数と12柱梁の断面2次王一メントを考元。他の变数は断面2次王一メントの

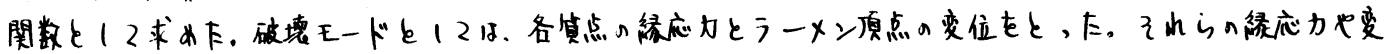

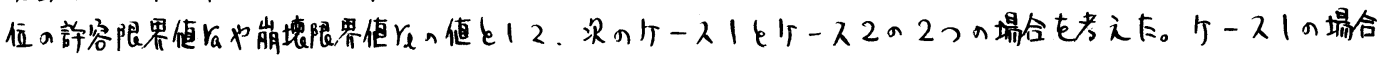

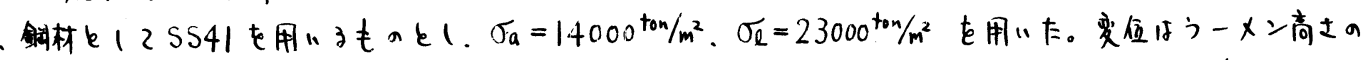

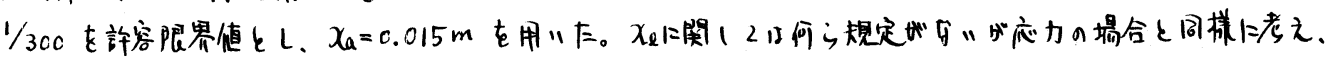

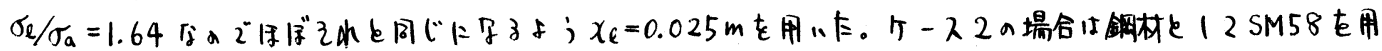

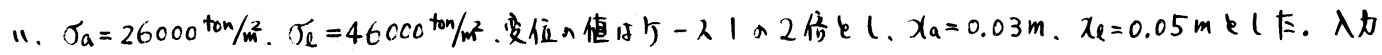

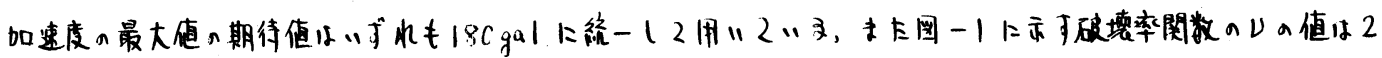

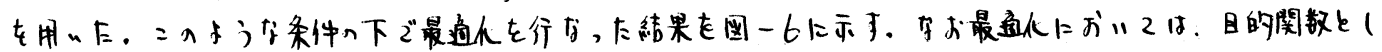

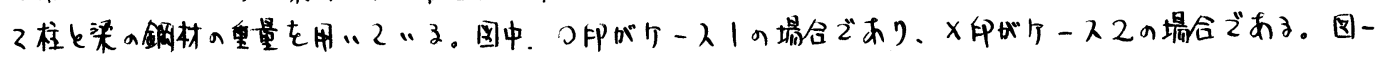

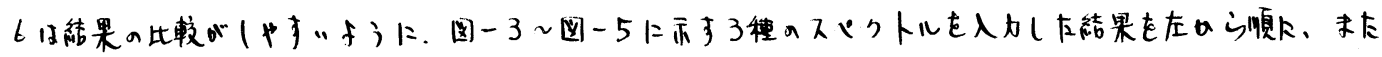

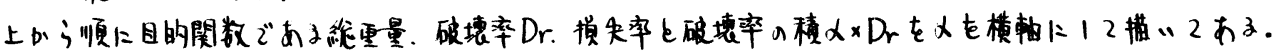

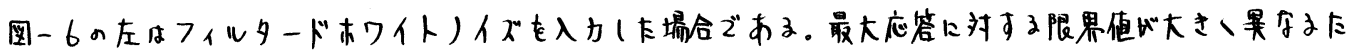

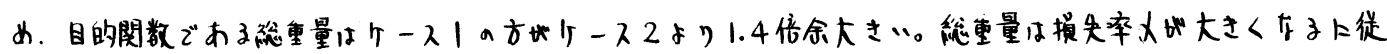



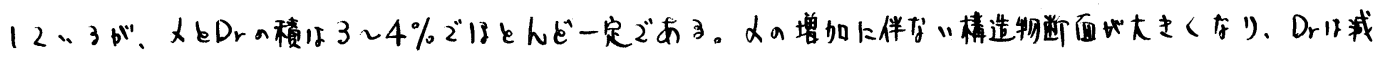





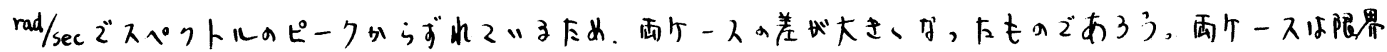



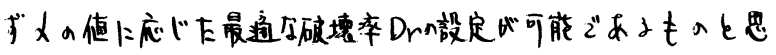

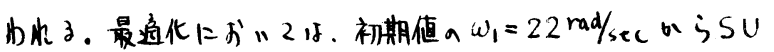
MTRよ，2 $\omega_{1}=39 \mathrm{rad} / \mathrm{sec} ま 2 ゙$ 断面が大きくすり，之の後順 次断面が小さく字，2最通解上收束(2おり。:うい, 下间题

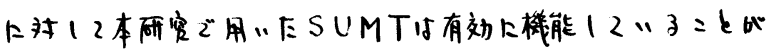

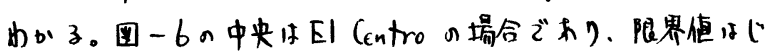

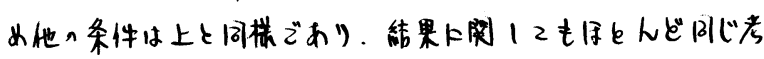

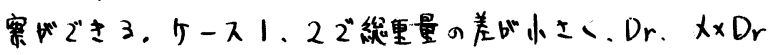

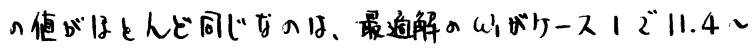

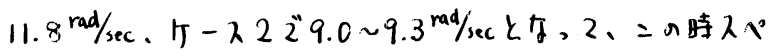


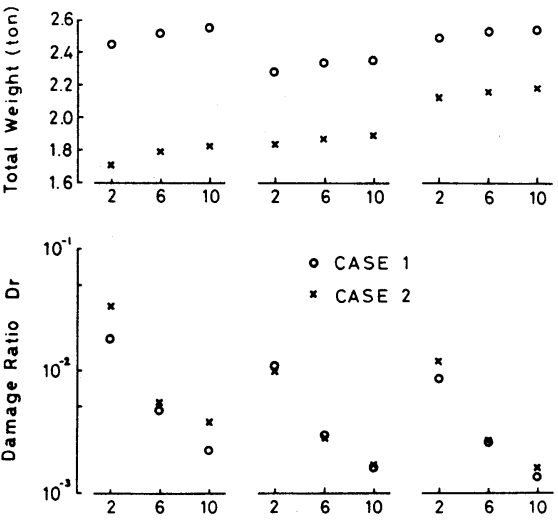


このようト入力のスアクトル特性上小，2最通解的当然整子



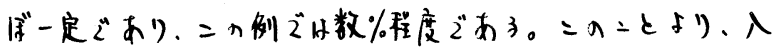

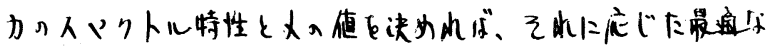
信楅性レベルを設定するンをが可能ですつう，

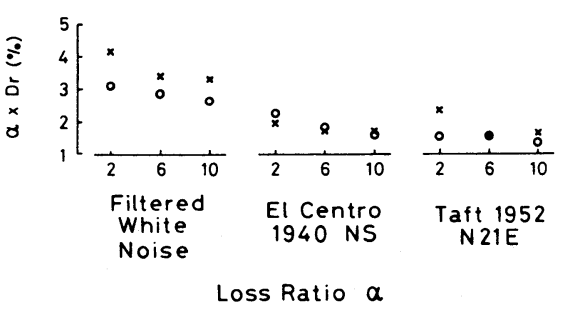




国ーフに示す吊㛢タワーピアー系に対し、国ー3に示すフィルタード ホワイトノイズを入力く計算を行な、下。計算に際い2、設計变数と し2多ワーの断面2次王ーメントとピアーの橋軸方问幅を避じ、多ワー

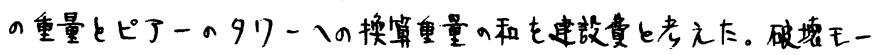



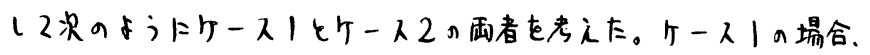

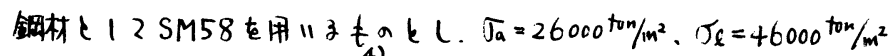

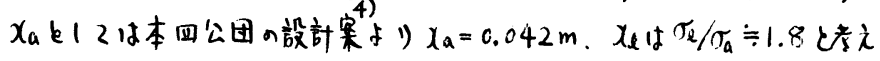

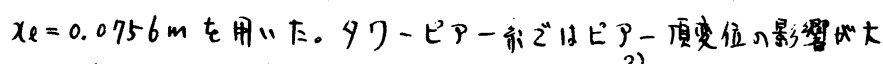





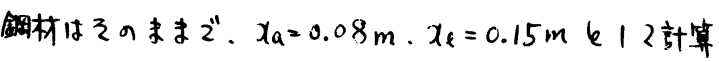

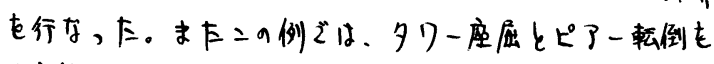

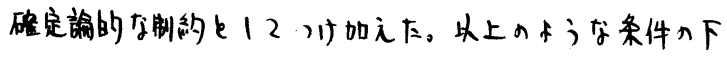

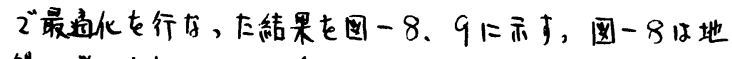


$30 \times 10^{4} \mathrm{ton} / \mathrm{m}^{2}$ の塥合である。両图子り、限界值の大小、地 盤の弹性定数の大小，损失率の大小により目的関数は大き

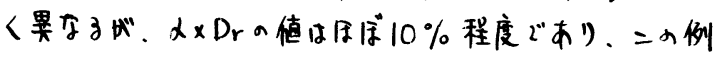

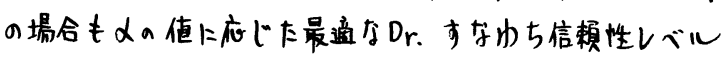
を設定することが可能である。

いし最通化の過程を詳しく模討すると、断面の少しい

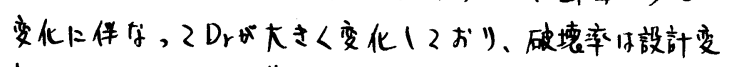
数に新にてか䒚り敏感な指標であることがわかる。当然の

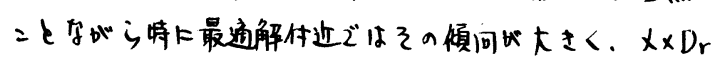

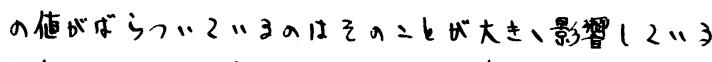


ボいいのでは尔いかと考えられる。

\section{4.あとがき}
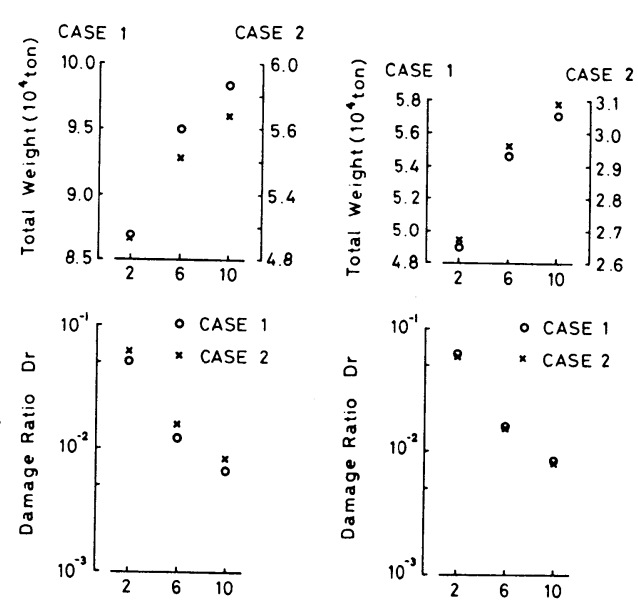

本研究は耐震放計に最通化の手法を通用し、模造物的初







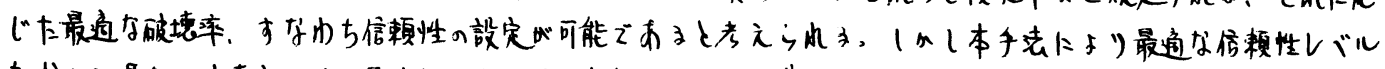

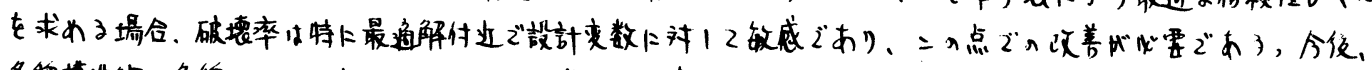

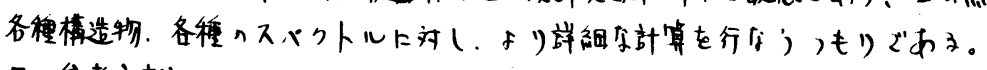

\section{5. 参考文献}

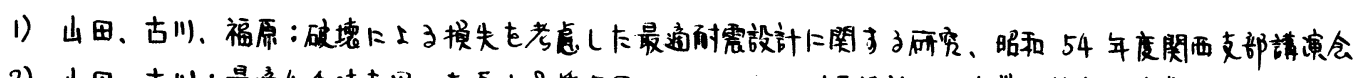

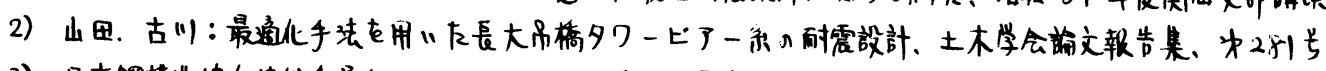

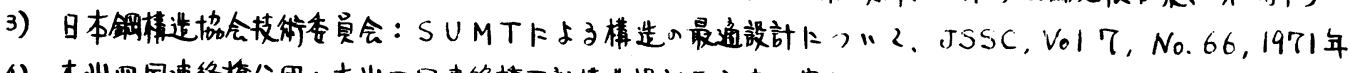

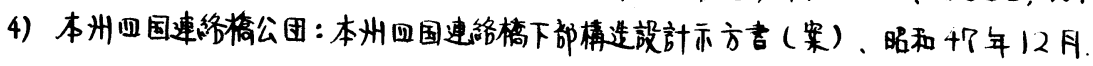

